Tropical Journal of Pharmaceutical Research November 2018; 17 (11): 2263-2267

ISSN: $1596-5996$ (print); 1596-9827 (electronic)

(C) Pharmacotherapy Group, Faculty of Pharmacy, University of Benin, Benin City, 300001 Nigeria.

\title{
Effect of serum cystatin $C$ and chromogranin $A$ on left ventricular mass index in patients with chronic heart failure
}

\author{
Xue Xiaoxuan, Liu Yan* \\ Dongfang Hospital, Beijing University of Traditional Chinese Medicine, No. 6, Fangxingyuan District 1, Fangzhuang District, \\ Fengtai District, Beijing 100078, China
}

*For correspondence: Email: hs1253@163.com

Sent for review: 10 July 2018

Revised accepted: 22 October 2018

\begin{abstract}
Purpose: To investigate the expression of serum cystatin $C$ (CystC) and chromogranin $A(C g A)$ in chronic heart failure (CHF) patients, and their correlation with left ventricular mass index (LVMI).

Methods: CHF patients (135) in the study hospital were randomly selected, and assigned to different groups on the basis of heart function grade (grades II to IV). Grades II, III and IV had 45 patients each. In addition, 45 people with normal physical examination results were assigned to the control group. In all patients, N-terminal natriuretic peptide (NT-proBNP), CysC and CgA were measured. In addition, left ventricular end-diastolic diameter (LVEDD), left ventricular end-diastolic volume (LVEDV), and left ventricular ejection fraction (LVEF) were measured using transthoracic echocardiography, and the results were used to calculate $L V M I$ values.

Results: There were significantly higher levels of CystC and CgA in CHF patients than in control patients $(p<0.05)$. In grade IV patients, CystC and CgA levels were higher than the corresponding levels in patients with cardiac function grades II and III, while their levels in grade III patients were higher than in grade II patients $(p<0.05)$. The results of correlation analysis indicated that serum CgA was positively correlated with serum CystC. Serum CgA and CystC levels in CHF patients were negatively correlated with LVEF, but positively correlated with NT-proBNP and LVMI levels.

Conclusion: Serum CgA and CysC are correlated with cardiac function grade and ventricular remodeling in CHF patients. Thus, to some extent, these two indices can be used to measure the degree of ventricular remodeling in CHF individuals.
\end{abstract}

Keywords: Chromogranin A (CgA), Heart failure, Cystatin C (CysC), Left ventricular mass index

This is an Open Access article that uses a funding model which does not charge readers or their institutions for access and distributed under the terms of the Creative Commons Attribution License (http://creativecommons.org/licenses/by/4.0) and the Budapest Open Access Initiative (http://www.budapestopenaccessinitiative.org/read), which permit unrestricted use, distribution, and reproduction in any medium, provided the original work is properly credited.

Tropical Journal of Pharmaceutical Research is indexed by Science Citation Index (SciSearch), Scopus, International Pharmaceutical Abstract, Chemical Abstracts, Embase, Index Copernicus, EBSCO, African Index Medicus, JournalSeek, Journal Citation Reports/Science Edition, Directory of Open Access Journals (DOAJ), African Journal Online, Bioline International, Open-J-Gate and Pharmacy Abstracts

\section{INTRODUCTION}

It has been established that $\mathrm{CHF}$ is caused by abnormal structure or function of the heart, leading to a decrease in cardiac output and low perfusion of peripheral tissues and organs [1-3].
The pathology of CHF is complicated, the death rate is high and the prognosis is poor in most cases. With developments in social economy, chronic heart failure now occurs in young individuals $[4,5]$. Recent studies have shown that ventricular remodeling is the basic mechanism 
involved in cardiac malfunction. Some scholars have reported that blood level of chromogranin $A$ $(\mathrm{CgA})$ in CHF patients is significantly increased after myocardial infarction, in addition to a correlation between $\mathrm{CgA}$ level and mortalities in VCHF patients $[6,7]$.

Moreover, a large number of studies have shown that increased levels of cystatin C (CystC) are associated with left ventricular concentric hypertrophy and increased left ventricular volume in $\mathrm{CHF}$ individuals. Incidents of left ventricular hypertrophy and diastolic dysfunction are elevated in response to increases in blood level of CystC. Studies have shown that the blood $\mathrm{CgA}$ concentrations in CHF patients increase significantly with severity of cardiac malfunction [8].

This study was carried out to investigate the expressions of serum CystC and $\mathrm{CgA}$ in $\mathrm{CHF}$ patients, and their correlation with ventricular remodeling.

\section{METHODS}

\section{Clinical data}

Patients with CHF (135) from January 2015 to December 2017 in our hospital were randomly selected and grouped according to heart function grade (grades II to IV). There were 45 cases in grade IV group, and 45 cases each in grades III and II. All patients were diagnosed with $\mathrm{CHF}$, and they met the NYHA diagnostic and cardiac function classification standards. In addition, 45 normal subjects were selected as control group.

This study received approval from the Ethical Committee of Dongfang Hospital, Beijing University of Traditional Chinese Medicine, China (approval no. 201879), and was implemented in line with Helsinki declaration of 1964 as amended in 1996 [9].

\section{Exclusion criteria}

The following categories of patients were excluded from the study: (1) subjects with severe liver and kidney disease, malignant tumor, immune system disease, connective tissue disease, acute infection, anemia, pregnancy and stroke; (2) subjects with stress-related mental disorders, paranoid mental disorders, bipolar affective disorders, split affective disorders, schizophrenia and other severe mental disorders; (3) cases of CHF due to causes other than coronary heart disease and hypertension; and (4) subjects who did not want to be enrolled in the project.

\section{Assessment of clinical parameters}

The body surface area of the selected patients was estimated on admission, and each patient provided information on the history of the disease. In the early morning of the next day after admission, overnight fasting venous blood was used for assaying NT-proBNP, liver and kidney function, lipid profiles and blood glucose. These indices were determined using fully automatic biochemical analyzer (Roche). Serum CystC and $\mathrm{CgA}$ were determined by ELISA in strict accordance with the instructions of the kit manufacturer. Values of LVEDV, LVEDD) and LVEF were measured using IE33 Color Ultrasound Diagnostic instrument (Philips). The results obtained were used to calculate LVMI.

\section{Statistical analysis}

Numeric data are presented as mean \pm standard deviation (SD). Multiple groups were compared with single factor ANOVA, while comparison between two groups were effected using LSD- $t$ test.. Count data are presented as percentage (\%), and were compared using Chi-square test. Data analyses were carried out using SPSS statistical software (version 18.0, IBM, USA). Values of $p<0.05$ were assumed to be statistically significant.

\section{RESULTS}

\section{General patient biodata}

As shown in Table 2, the CHF patients did not differ significantly from normal control group with respect to age, sex and $\mathrm{BMI}(p>0.05)$.

Table 1: General patient profile $(n=45)$

\begin{tabular}{|c|c|c|c|}
\hline Group & $\begin{array}{l}\text { Age } \\
\text { (years) }\end{array}$ & Male/female & $\begin{array}{l}\text { BMI } \\
\left(\mathrm{kg} / \mathrm{m}^{2}\right)\end{array}$ \\
\hline $\begin{array}{l}\text { Grade } \\
\text { NYHA II } \\
\text { group }\end{array}$ & $\begin{array}{l}62.18 \pm \\
7.29\end{array}$ & $24 / 21$ & $\begin{array}{l}24.05 \pm \\
2.65\end{array}$ \\
\hline $\begin{array}{l}\text { Grade } \\
\text { NYHA III } \\
\text { group }\end{array}$ & $\begin{array}{l}63.91 \pm \\
8.01\end{array}$ & $22 / 23$ & $\begin{array}{l}23.65 \pm \\
1.37\end{array}$ \\
\hline $\begin{array}{l}\text { Grade } \\
\text { NYHA IV } \\
\text { group }\end{array}$ & $\begin{array}{l}62.48 \pm \\
8.46\end{array}$ & $26 / 19$ & $\begin{array}{l}24.36 \pm \\
2.01\end{array}$ \\
\hline $\begin{array}{l}\text { Control } \\
\text { group }\end{array}$ & $\begin{array}{l}63.05 \pm \\
9.26\end{array}$ & $25 / 20$ & $\begin{array}{l}24.51 \pm \\
1.98\end{array}$ \\
\hline$F / X^{2}$ & 0.380 & 0.783 & 1.543 \\
\hline$p$ & 0.768 & 0.854 & 0.205 \\
\hline
\end{tabular}




\section{NT-proBNP, CystC and CgA levels}

Table 2 shows that there were significant upregulations in CystC, $\mathrm{CgA}$ and NT-proBNP in CHF cases, relative to control cases $(p<0.05)$. In addition, NT-proBNP, CystC and CgA in cardiac function grade IV were higher than in patients with cardiac function grades II and III ( $p$ $<0.05)$. They were also higher in cardiac function grade III patients than in cardiac function grade II cases $(p<0.05)$.

\section{Cardiac function indices}

The CHF patients had higher LVEF, LVEDD and LVMI values than control group patients, their LVEF level decreased, when compared with that of the control group $(p<0.05)$ (Table 3$)$. With aggravation of cardiac function, LVMI, LVEDD increased gradually, while LVEF decreased. There were significant differences between groups $(p<0.05)$.

\section{Correlation between CystC and $\mathrm{CgA}$, and cardiac function indices}

Serum $\mathrm{CgA}$ and CystC levels were negatively correlated with LVEF in CHF patients $(r=-0.78$, $0.73, p<0.05$ ). However, there was positive correlation between serum $\mathrm{CgA} / \mathrm{CystC}$, and NTproBNP/LVMI $(r=0.81,0.89,0.76,0.85, p<0$. 05).

\section{DISCUSSION}

Recent investigations revealed that ventricular remodeling is the basic mechanism involved in heart failure. The pathological changes in ventricular remodeling include extracellular matrix remodeling and myocardial remodeling $[10,11]$. A recent study revealed that the content of chromogranin $\mathrm{A}(\mathrm{CgA})$ was elevated in $\mathrm{CHF}$ patients after myocardial infarction, with correlation between $\mathrm{CgA}$ level and mortality. In addition, several workers have reported that elevated CystC is related to left ventricular concentric hypertrophy and increased left ventricular volume in CHF patients. Therefore, $\mathrm{CgA}$ and CystC may be used to assess the severity of chronic heart failure [12,13].

The expressions of serum CystC and $\mathrm{CgA}$ in CHF patients, and their correlation with LVMI, were investigated in this study so as to generate data for application in the treatment and prevention of CHF. Chromogranin A $(\mathrm{CgA})$ is a very important endogenous cathepsin inhibitor which provides a dynamic equilibrium by regulating the production and degradation of extracellular vascular matrix [14]. An important mechanism involved in the development of ventricular remodeling in CHF patients is the imbalance in the ratio of cathepsin and endogenous protease inhibitors in extracellular matrix of cardiomyocytes [15].

When increased synthesis occurs, collagen accumulates around the myocardial vessels and in the intercellular substance. When excessive degradation occurs, the original physiological collagen scaffold will be destroyed, and the composition and structure extracellular matrix will also be changed.

Table 2: NT-proBNP, CysC and CgA levels in patients (mean $\pm \mathrm{SD}, \mathrm{N}=45$ )

\begin{tabular}{lccc}
\hline Group & $\mathbf{C g A}(\mathbf{n g} / \mathbf{m l})$ & CysC $(\boldsymbol{\mu g} / \mathbf{L})$ & NT-proBNP $(\mathbf{p g} / \mathbf{m l})$ \\
\hline Grade NYHA group & $136.28 \pm 12.66^{*{ }_{\Delta}}$ & $819.44 \pm 17.28^{* \#} \Delta$ & $6482.41 \pm 471.26^{* \# \Delta}$ \\
Grade NYHA III group & $226.49 \pm 15.82^{*} \#$ & $1027.3 \pm 41.46^{* \#}$ & $7082.77 \pm 428.48^{* \#}$ \\
Grade NYHA IV group & $311.24 \pm 22.71^{*}$ & $1164.4 \pm 43.28^{*}$ & $7894.28 \pm 455.62^{*}$ \\
Control group & $72.88 \pm 4.72$ & $702.52 \pm 13.60$ & $1538.64 \pm 182.74$ \\
$F$ & 2061.46 & 1890.41 & 2286.77 \\
$P$ & $<0.001$ & $<0.001$ & $<0.01$ \\
\hline$p<0.05$, relative to control; ${ }^{\#} p<0.05$, relative to NYHA IV; ${ }^{*} p<0.05$, relative to NYHA III
\end{tabular}

Table 3: LVEF, LVEDD and LVMI levels (mean $\pm S D, N=45$ )

\begin{tabular}{lccc}
\hline Group & LVEF (\%) & LVMI & LVEDD/mm \\
\hline Grade NYHA II group & $41.38 \pm 9.67^{\#_{\Delta}}$ & $131.42 \pm 12.44^{*{ }_{\Delta}}$ & $53.91 \pm 7.24^{\#_{\Delta}}$ \\
Grade NYHA III group & $41.66 \pm 7.82^{* \#}$ & $142.37 \pm 14.81^{\#}$ & $57.52 \pm 8.92^{* \#}$ \\
Grade NYHA IV group & $36.50 \pm 6.39^{*}$ & $158.87 \pm 15.05^{*}$ & $62.03 \pm 8.28^{*}$ \\
Control group & $54.11 \pm 5.37$ & $106.29 \pm 12.36$ & $50.02 \pm 6.36$ \\
$F$ & 44.17 & 116.35 & 19.63 \\
$P$ & $<0.001$ & $<0.001$ & $<0.001$ \\
\hline${ }^{*} P<0.05$, relative to control: ${ }^{*} p<0.05$, relative to NYHA IV $\cdot \Delta p<0.05$, relative to NYHA III
\end{tabular}


The patient eventually develops heart failure due to myocardial fibrosis and ventricular remodeling. It has been found that an increased level of serum CystC leads to increased diastolic dysfunction and left ventricular hypertrophy.

In this study, the levels of CystC and $\mathrm{CgA}$ were markedly higher in CHF patients than in control patients. The levels of CystC and $\mathrm{CgA}$ in patients with cardiac function grade IV were higher than those in patients with cardiac function grades II and III, and also higher in cardiac function grade III than in cardiac function grade II cases. The level of LVEF in cases with elevated $\mathrm{CgA}$ and CystC was significantly reduced, with significant elevation in LVEDD, LVMI and NT-proBNP, relative to control. This is consistent with the results of similar studies [16-22]. These findings indicate that, to some extent, CystC and CgA may serve as indices of extent of ventricular remodeling in CHF patients, as well as their prognosis. In addition, the results of correlation analysis indicated positive correlation between serum $\mathrm{CgA}$ and serum CystC. Correlation analysis revealed negative correlation between $\mathrm{CgA}$ and CystC levels in serum and LVEF, and positive correlation of LVMI with NT-proBNP in $\mathrm{CHF}$ patients. There were positive correlations between serum CystC level and levels of LVEDD, LVMI, NT-proBNP and CgA in CHF. The levels of $\mathrm{CgA}$ and CystC increased with decrease in cardiac function and increase in myocardial weight and heart enlargement. These results suggest that serum $\mathrm{CgA}$ and $\mathrm{Cyst} C$ levels in CHF patients can be used for evaluating the severity of heart failure, at least to some extent.

\section{CONCLUSION}

Serum $\mathrm{CgA}$ and CystC levels are correlated with cardiac function grade and ventricular remodeling in $\mathrm{CHF}$ patients. Thus, to some extent, these two indices can serve as criteria for assessing the severity of ventricular remodeling in CHF patients.

\section{DECLARATIONS}

\section{Acknowledgement}

This work was supported with grants from the National Science Foundation of China (NSFC, no. 81404790).

\section{Conflict of interest}

No conflict of interest is associated with this work.

\section{Contribution of authors}

We declare that this work was done by the author(s) named in this article and all liabilities pertaining to claims relating to the content of this article will be borne by the authors, all authors read and approved the manuscript for publication. Liu Yan conceived and designed the study, Xue Xiaoxuan, Liu Yan collected and analyzed the data, Xue Xiaoxuan wrote the manuscript.

\section{REFERENCES}

1. Liu $Q$, Hu H, Hu T, Han T, Wang A, Huang L, Tan Q, Tan W. STVNa attenuates right ventricle hypertrophy and pulmonary artery remodeling in rats induced by transverse aortic constriction. Biomed Pharmacother 2018; 101: 371.

2. Liu ZX. Clinical Observation of Valsartan or Benazepril Combined with Atorvastatin in the Treatment of Chronic Heart Failure. Guide China Med 2017; (31): 27-28.

3. van HH, Cowie MR, Van DMP. Sleep-disordered breathing and chronic heart failure: changing position may be important. Eur J Heart Fail 2016; 17(12): 12191222.

4. Welsh P, Kou L, Yu C, Anand I, Veldhuisen DJ, Maggioni $A P$, Desai AS, Solomon SD, Pfeffer MA, Cheng $S$, et al. Prognostic importance of emerging cardiac, inflammatory, and renal biomarkers in chronic heart failure patients with reduced ejection fraction and anaemia: RED-HF study. Eur J Heart Fail 2018; 20(2): 268-277.

5. He XB, Wen $Z H$, Liu $X L$, Pan $Z$, Wang $Q$, Huang MJ. Evaluation of Clinical Efficiency of Yangxin Tongmai Yin on Left Ventricular Remodeling in Chronic Heart Failure Patients by Real-time Three-dimensional Echocardiography. J Guangzhou Univ Tradit Chin Med 2016; 33(6): 772-775.

6. Wu HD. Relationship between serum NT-proBNP level and rehospitalization rate and survival rate in patients with chronic heart failure. Chin J Gerontol 2016; 36(2): 338-339.

7. Iranirad L, Sadeghi MS, Bagheri A, Doostali K, Norouzi S, Hejazi SF, Saghafi H, Sakineh RM. Allopurinol prophylactic therapy and the prevention of contrastinduced nephropathy in high-risk patients undergoing coronary angiography: $A$ prospective randomized controlled trial. ARYA Atheroscler 2017; 13(5): 230-235.

8. Zand F, Sabetian G, Abbasi G, Salehi A, Khosravi A, Geramizadeh B, Taregh SU, Javadpour S. Early Acute Kidney Injury based on Serum Creatinine or Cystatin C in Intensive Care Unit after Major Trauma. Iran J Med Sci 2015; (6): 485-492.

9. World Health Organization. Declaration of Helsinki. Br Med J 1996; 313(7070): 1448-1449.

10. Huang Y, Xiao J, Xu J, Cardiology DO. The variation and significance of plasma BNP in the DCM patients with

Trop J Pharm Res, November 2018; 17(11): 2266 
chronic heart failure. Acta Univ Med Anhui 2016; 51(3): 435-438.

11. Otaki Y, Takahashi H, Watanabe T, Yamaura G, Funayama A, Arimoto $T$, Shishido $T$, Miyamoto $T$, Kubota I. Cystatin C-Based eGFR Is a Superior Prognostic Parameter to Creatinine-Based eGFR in Post-Endovascular Therapy Peripheral Artery Disease Patients. Circ J 2015; 79(11): 2480-2486.

12. Machado JD, Camargo EG, Boff R, Rodrigues LDS, Camargo JL, Soares AA, Silveiro SP. Combined creatinine-cystatin C CKD-EPI equation significantly underestimates measured glomerular filtration rate in people with type 2 diabetes mellitus. Clin Biochem 2018; 53: 43-48.

13. Yang $X O$, Zhang MY, Li XH, Feng $X$, Peng $Y$. Expression of platelet-derived growth factor- $B B$ and connective tissue growth factor in renal tissues of rats with chronic heart failure. Chin J Anat 2016; 39(2): 161-165.

14. Li LG, Zhang YM. Efficacy and safety of moderate salt supplementation in patients with chronic heart failure complicated with hyponatremia. Prev Treat CardioCerebral-Vascular Dis 2016; 16(2): 143-144.

15. Gao XF, Li JD, Guo L, Guo SS, Zhang R, Gou YL, Chen $H$. Effect of Hybrid Blood Purification Treatment on Secondary Hyperparathyroidism for Maintenance Hemodialysis Patients. Blood Purif 2018; 46(1): 19-26.
16. Cheng $Y Y$, An JD, Feng $S$, Ge W. Changes in serum chromogranin $A$ and urotensin II levels in children with chronic heart failure. Chin J Contemp Pediatrics 2017; 19(3): 313-317.

17. European Journal of Heart Failure. [homepage on the Internet]. Wiley Online Library; c2016 [cited 2018 Oct 2]. Available from: https://onlinelibrary.wiley.com/doi/abs/ 10.1002/ejhf.539.

18. European Journal of Heart Failure. [homepage on the Internet]. Wiley Online Library; c2016 [cited 2018 Oct 2]. Available from: https://onlinelibrary.wiley.com/doi/abs/ 10.1002/ejhf.277.

19. European Journal of Heart Failure. [homepage on the Internet]. Wiley Online Library; c2016 [cited 2018 Oct 2]. Available from: https://onlinelibrary.wiley.com/doi/abs/ 10.1093/eurjhf/hst009.

20. Xin H, Jianan W. Up-regulation of endogenous leptin improves human mesenchymal stem cell survival ability in vitro and this cells protect fatal cardial myocytes from apoptosis. Heart 2012; 98(Suppl 2): 167-167.

21. Sun Y, Tian Y, Prabha M, Liu D, Chen S, Zhang R, Liu X, Tang $C$, Tang $X$, Jin $H$, et al. Effects of sulfur dioxide on hypoxic pulmonary vascular structural remodeling. Lab Invest 2010; 90(1): 68-82. 